\title{
Nadir bir hemotokezya olgusunda farklı bir tedavi yaklaşımı
}

\author{
Alternative treatment of a rare cause of hematochezis
}

A. Emre YILDIRIM, Reskan ALTUN, Serkan ÖCAL, Enver AKBAŞ, Murat KORKMAZ, Haldun ŞELÇUK, Uğur YILMAZ

Başkent Üniversitesi Tip Fakültesi, Gastroenteroloji Bilim Dall, Ankara

Hematokezya çoğunlukla kolon kaynaklı kanamayı gösterir. Fakat özellikle ciddi hematokezya üst gastrointestinal sistem kökenli bir kanamadan da kaynaklanabilir. Burada nadir bir hematokezya nedeni olarak kardiada kanayan polibi olan ve tedavisinde de başarılı endoskopik bant ligasyonu uygulanan bir hastayı bildiriyoruz.

\section{Anahtar kelimeler: Hematokezya, bant ligasyonu}

\section{GİISS}

Akut gastrointestinal sistem kanamaları (GISK) morbidite ve mortalitesi yüksek ciddi bir klinik durumdur. Endoskopik incelemelerin rutin kullanıma girmesi ile GISK'nın tanı ve tedavisinde ilerlemeler kaydedilmiştir. Endoskopik tedaviler içerisinde vazokonstrüktör ajan enjeksiyonu, termal ablasyon ve mekanik tedaviler yer almaktadır. Bu yöntemlerin tek veya kombine kullanılması tekrar kanama riskini, cerrahi müdahale ve kan transfüzyon ihtiyacını azaltarak hastane yatış süresini kısaltır hatta mortaliteyi bile olumlu yönde etkileyebilir.

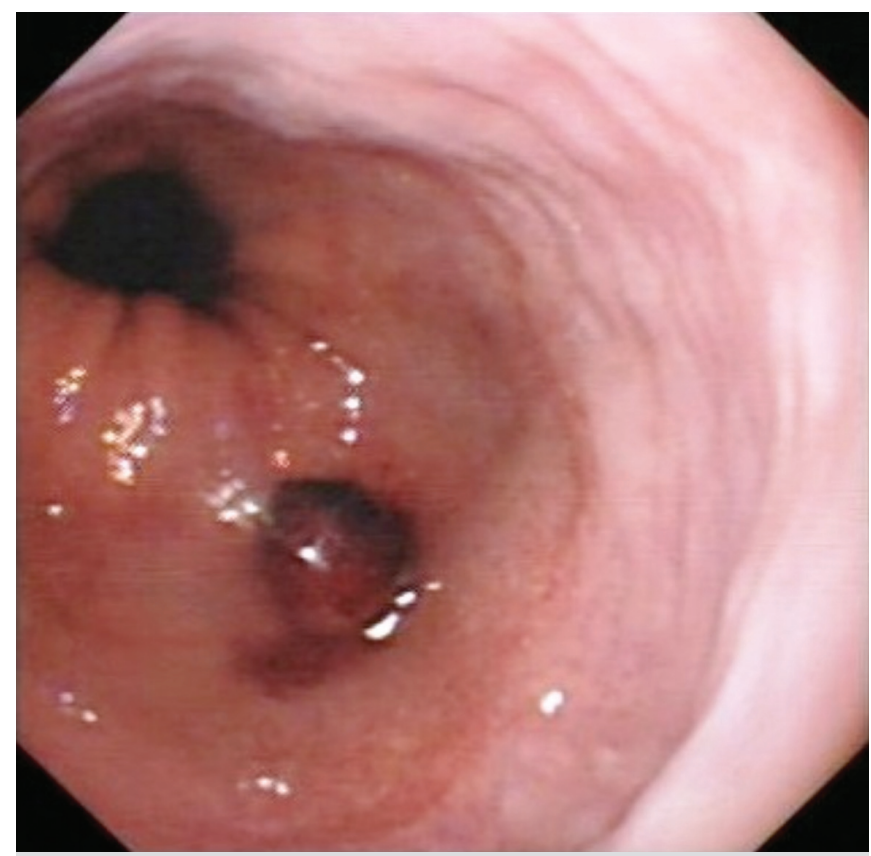

Resim 1. Üzeri dejenere ve yapışık pıhtılı polip.
Although hematochezia generally indicates bleeding from colonic lesions, serious hematochezia can result from the upper gastrointestinal system as well. Here, we report a rare but serious case of upper gastrointestinal hemorrhage from a cardiac polyp presenting with hematochezia. The patient was successfully treated with endoscopic band ligation.

Key words: Hematochezia, band ligation

\section{OLGU SUNUMU}

Son 3 gündür ateş yüksekliği, öksürük ve balgam şikâyeti olan 72 yaşındaki kadın hasta acil servise başvurdu. Alzheimer hastalığı nedeni ile oral yol ile beslenemeyen hastaya 5 gün önce başka bir merkezde perkütan endoskopik gastrostomi (PEG) açılarak enteral nutrisyon başlandığı öğrenildi. Fizik muayenesinde hastanın oryantasyonu ve kooperasyonu bozuktu. Vücut sıcaklığı 38,5 Co, kan basincı 155/100 mmHg, solunum sayısı 28/dk, nabız 105 atım/dk ölçüldü. Orofarinks hiperemik idi. Dil üzerinde beyaz eksuda ile kap-

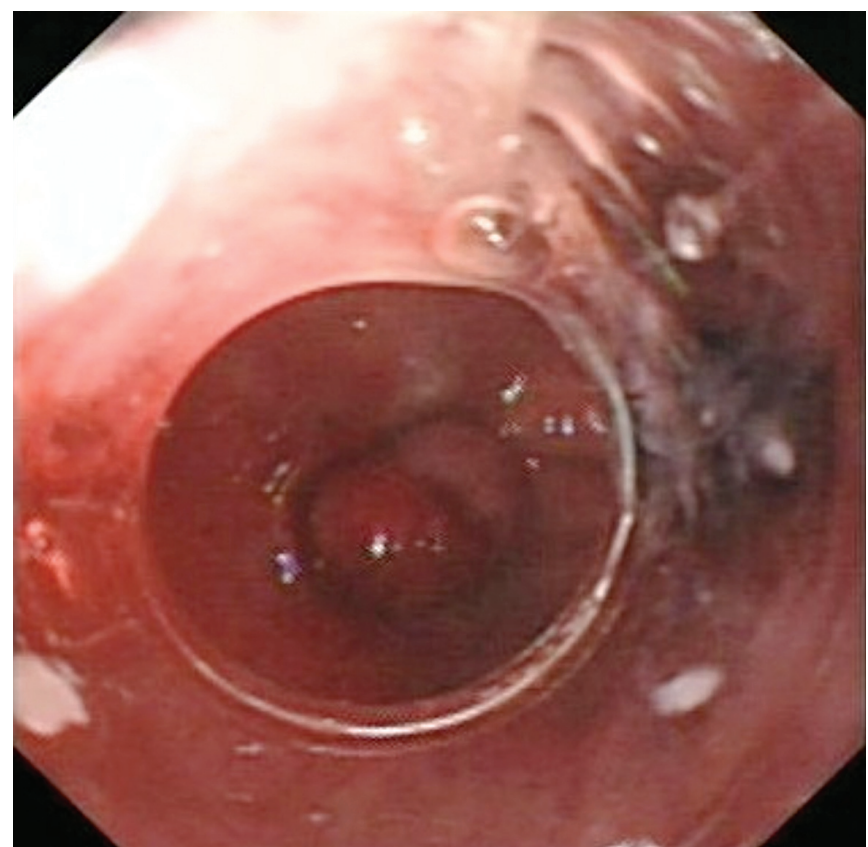

Resim 2. EBL sonrası polipin görünümü.

Iletişim: A. Emre YILDIRIM Başkent Üniversitesi Tip Fakültesi Gastroenteroloji Bilim Dalı, Ankara Hastanesi Fevzi Çakmak Caddesi 10. Sokak No:45 06490 Bahçelievler / Ankara / Türkiye Tel: + 9031221268 68/1205 • Faks: + 9031222373 33 E-mail: draemreyildirim@gmail.com 
lı ülsere lezyonlar izlendi. Solunum sistemi muayenesinde sağ hemitoraksta belirgin bilateral krepitan raller oskülte edildi. Karın muayenesinde PEG kateterinin ciltten giriş yeri temiz görünümde idi. Laboratuar tetkiklerinde Hb:10,2 g/dl, Beyaz küre: 16400 /UL, Trombosit: 346 bin/ UL, INR: 1.46, BUN: 49 mg/dl, Kreatinin: 0,9 mg/dl, ALT: 322 U/L, AST: 339 U/L, ALP: 296 U/L, GGT: 49 U/L, CRP: 328 mg/L idi. Toraks bilgisayarlı tomografi (BT) incelemesinde; sağ ve sol pulmoner arter dallarında kronik dönemde fokal trombüs ve her iki akciğer alt lobda sağda atelektazinin de eşlik ettiği pnömonik infiltrasyon ile uyumlu konsolidasyon alanları izlendi. Abdomen BT incelemesinde; karın ön duvarından mideye uzanım gösteren gastrostomi kateteri dışında patoloji izlenmedi.

Hasta bu bulgular ile Göğüs Hastalıkları Bölümü tarafından değerlendirildi. Aspirasyon pnömonisi ve pulmoner tromboemboli tanıları ile yoğun bakım ünitesine yatırıldı. Geniş spektrumlu antibiyotik ve düşük molekül ağırlıklı heparin başlandı. Takiplerinde hastanın enfeksiyonu kontrol altına alındı ve genel durumu düzeldi. Tedavinin 10. gününde hematokezyası olan, hemodinamisi hızla bozulan hastanın kontrol tam kan tetkikinde hemoglobin değerinin 6,6 g/dl'ye gerilediği görüldü. Üst gastrointestinal sistem (GIS) endoskopisi yapılan hastanın özofagus distalinde $\mathrm{Z}$ çizgisine komşu yaklaşık $15 \mathrm{~mm}$ çapında üzeri dejenere ve yapışık pıhtılı polip izlendi (Resim 1). Bu lezyonun kanamaya neden olduğu düşünülerek band ligasyonu yapıldı (Resim 2). Hastanın hemostaz parametrelerinin bozuk olması ve kanamaya ciddi eğilimi olmasından dolayı polip snare ile kesilerek dışarıya alınmadı. İşlem sonrası yapılan takipte hastanın hemodinamisi düzeldi ve kanama tekrarlamadı. On gün sonra yapılan kontrol endoskopisinde polipin ligasyonu sonrası düştüğü ve hafif skar ile iyileştiği görüldü (Resim 3).

\section{TARTISMA}

Hematokezya çoğunlukla kolon kaynaklı kanamayı gösterir. Fakat olguların \%1l'i treitz ligamentinin proksimalinden,

\section{KAYNAKLAR}

1. Current Diagnosis \& Treatment in Gastroenterology Ed: Friedman, Scott L.; McQuaid, Kenneth R.; Grendell, James H. Publisher: McGraw-Hill Edition: 2nd Edition.

2. Garcia-Tsao G, Sanyal AJ, Grace ND, et al. Prevention and management of gastroesophageal varices and variceal hemorrhage in cirrhosis. Hepatology 2007; 46: 922-38.

3. Misra SP, Dwivedi M, Misra V, et al. Endoscopic band ligation as salvage therapy in patients with bleeding peptic ulcers not responding to injection therapy. Endoscopy 2005; 37: 626-9.

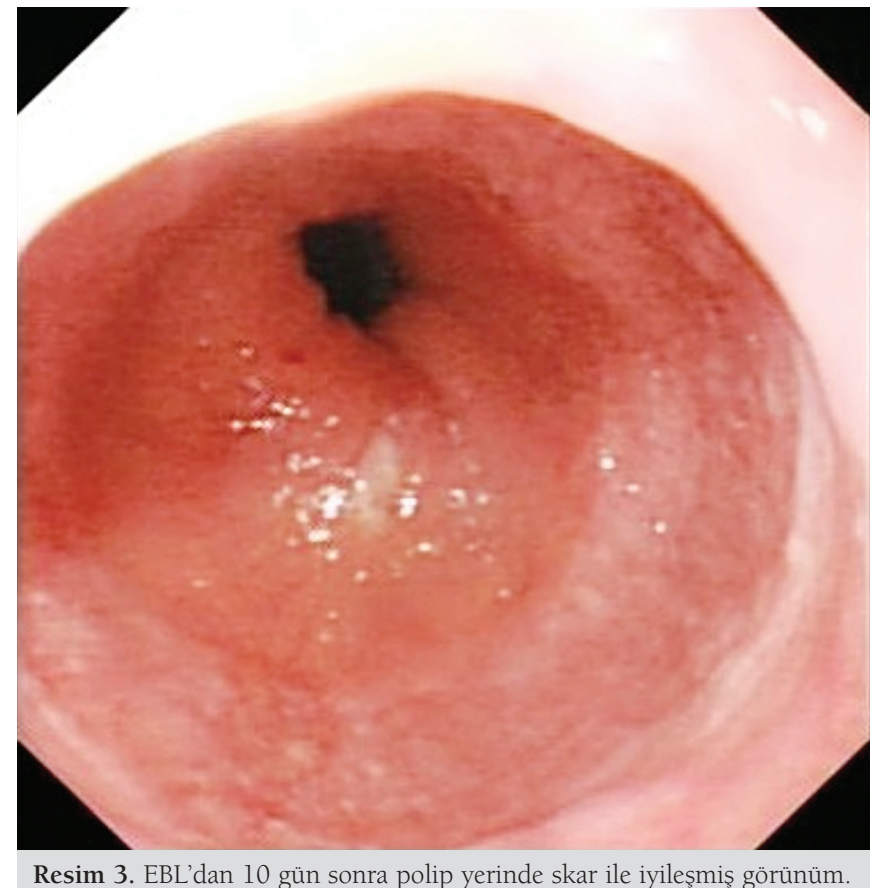

Resim 3. EBL'dan 10 gün sonra polip yerinde skar ile iyileşmiş görünüm.

\%9'u ise ince barsaktan kaynaklanır. Tüm taramalara rağmen hastaların \%6'sında odak saptanamaz. Üst GİS kaynaklı hematokezyası olan hastalarda ciddi kanamanın klinik bulgusu olarak hemodinami bozulur (1). Masif hematokezya nedeni ile değerlendirdiğimiz hastamızda nadir bir neden olan kardiada kanayan polip tespit edildi. Endoskopik band ligasyonu (EBL) sonrası kanama başarı ile kontrol altına alındı.

EBL primer ve sekonder özofagus varis profilaksisi ile özofagus varis kanamasında sık kullanılan bir yöntemdir (2). Ayrıca EBL'nun fundus varislerinin tedavisinde, peptik ülser, Mallory-Weiss ve Dieulafoy lezyonları kanamalarında kullanıldığı çalışmalar yayınlanmıştır (3-5). Ancak bu konudaki deneyim çok sınırlıdır. Üst GIS'de kanayan poliplere EBL uygulamasının güvenilir ve etkili olduğu, bu nedenle bu tür kanamaların kontrolünde de kullanılabileceği kanaatindeyiz.

4. Lecleire S, Antonietti M, Iwanicki-Caron I, et al. Endoscopic band ligation could decrease recurrent bleeding in Mallory-Weiss syndrome as compared to haemostasis by hemoclips plus epinephrine. Aliment Pharmacol Ther 2009; 30: 399-405.

5. Alis $\mathrm{H}$, Oner OZ, Kalayci MU, et al. Is endoscopic band ligation superior to injection therapy for Dieulafoy lesion? Surg Endosc 2009; 23: $1465-9$ 